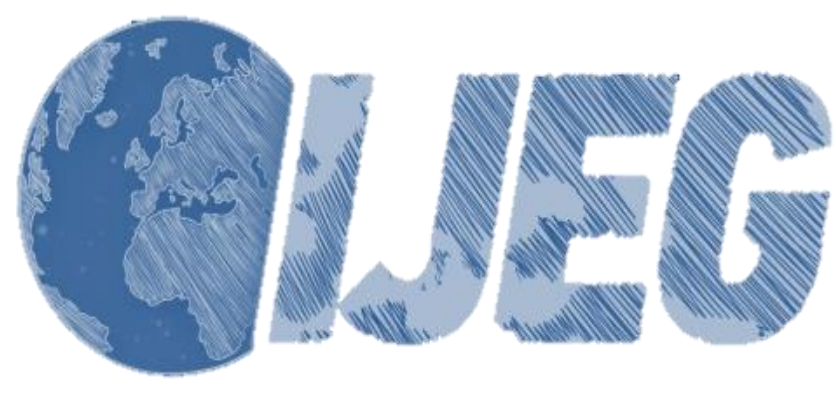

International Journal of Engineering and Geosciences (IJEG), Vol; 5, Issue; 2, pp. 094-099, June, 2020, ISSN 2548-0960, Turkey, DOI: 10.26833 ijeg. 614856

\title{
A NOVEL APPROACH FOR IONOSPHERIC TOTAL ELECTRON CONTENT EARTHQUAKE PRECURSOR AND EPICENTER DETECTION FOR LOW- LATITUDE
}

\author{
Santanu Kalita ${ }^{1 *}$, Bornali Chetia ${ }^{2}$
}

\author{
${ }^{1}$ Department of Computer Application, Mahapurusha Srimanta Sankaradeva Viswavidyalaya, Assam, India \\ (santanu.kalita@ rediffmail.com); ORCID 0000-0003-2715-9225 \\ ${ }^{2}$ Department of Physics, Royal Global University, Assam, India \\ (bornalichetia.physics@gmail.com); ORCID 0000-0002-9997-0300
}

*Corresponding Author, Received: 03/09/2019, Accepted: 21/09/2019

\begin{abstract}
The earthquake precursory phenomena detection using ionospheric perturbation characteristics is a new technique used by the scientist now days. This paper focuses a new technique for detecting any modification in the time series profile shape caused by an impending earthquake to identify precursors as well as an image processing technique for epicenter detection. For this purpose IGS Global Navigation Satellite System (GNSS) Total Electron Content Data (TEC) are utilized from different stations across the world. From the experiment it is observed that the method may detect earthquake precursors a few hours or days prior to the main event due to ionospheric perturbations induced by initiation of earthquake process.
\end{abstract}

Keywords: GNSS, Total Electron Content, ionosphere 


\section{INTRODUCTION}

The ionospheric variability has been used as a precursor marker for an impending earthquake by several researchers around the globe (ChuoY.J.Y, 2001; J. Y. Liu 2000; Yuri Ruzhin, 2007). The ionospheric irregularity and seismic event relations are detected through various parameters like fof2, ionospheric density measurement, very high frequency, Total Electron Content (TEC) etc. Out of these parameters TEC data are widely used for earthquake precursor studies. TEC is the measure of the total amount of electrons along a particular line of sight, i.e., from the satellite to the receiver and the unit of total electron content is TECU where 1TECU $=10^{16}$ electrons $/ \mathrm{m} 2$. The Global Positioning System (GPS) is the popular system which is used in estimation of TEC which provides the estimate for the total number of electrons on the receiver-satellite link. The TEC of the ionosphere varies with space and time and the behavior depended on other geomagnetic activities like geomagnetic storm, sun solar activity and the location of receiving station. During the earthquake preparatory process, due to the movement of tectonic plates positive ions are produced which travels through troposphere to ionosphere and joins electrons which leads to high TEC values. Several studies have reported the GPS derived TEC variations before the occurrence of large earthquakes (E. Calais et al, 1995; G K. Davies et al, 1965; M. Hayakawa, 1999; V. N. Oraevsky et al; S. Kalita, 2015). Some of important cases include 17 August 1999 of magnitude 7.6M Izmit earthquake, 12 May 2008 8.0M magnitude Wenchuan earthquake, 12 January $2010 \mathrm{M}=17$ Haiti earthquake and 11 March $2011 \mathrm{Mw} 9$ Tohoku earthquake which describes anomalous TEC variation before the earthquake events (Dogan, U et al, 2011; Zhang, 2008; Liu, 2011, Dimitar, 2011). In India, attempts have been made by S Kalita (S Kalita et al., 2015), Dutta (Dutta et al., 2007) and Priyadarshi, (Priyadarshi et al. 2011) to find the relation between TEC variations and seismic activities.

\section{DATA AND ANALYSIS}

It has been observed that by analyzing ionospheric TEC, one can detect earthquake precursors in a few hours or days prior to the main event due to ionospheric perturbations induced by initiation of earthquake process. For this purpose, in this work, the nearest GNSS stations of the earthquake events described in Table 1 are considered for analyzing and processing. The International GNSS Service (IGS) is located in different parts of the world and various data analysis centers provides high-quality GPS data and data products in near real time for scientific and engineering works. The data from Crustal Dynamics Data Information System (CDDIS), National Aeronautics and Space Administration (NASA) were used for TEC estimation in raw format and then it is pre-processed and converted to RENIX format and processed to obtain TEC values using GPS-TEC program (C. Noll, 2010).

\begin{tabular}{|c|l|l|l|l|}
\hline $\begin{array}{c}\text { Date of } \\
\text { earthquake } \\
\text { event }\end{array}$ & Epicentre & Magnitude & $\mathrm{Kp}$ & $\begin{array}{l}\text { Nearest } \\
\text { Station }\end{array}$ \\
\hline $21 / 09 / 2009$ & $\begin{array}{l}27.32^{\circ} \mathrm{N}, \\
91.42^{\circ} \mathrm{E}\end{array}$ & $5 \mathrm{Mw}$ & 13 & $\begin{array}{l}\text { Lasha, } \\
\text { Chaina }\end{array}$ \\
\hline $10 / 08 / 2010$ & $\begin{array}{l}14.013^{\circ} \mathrm{N} \\
92.923^{\circ} \mathrm{E}\end{array}$ & $7.5 \mathrm{Mw}$ & 6 & $\begin{array}{l}\text { Lasha, } \\
\text { Chaina }\end{array}$ \\
\hline $13 / 04 / 2009$ & $\begin{array}{l}33.165^{\circ} \mathrm{N} \\
6\end{array}$ & $7.1 \mathrm{Mw}$ & 5 & $\begin{array}{l}\text { Andaman } \\
\text { and } \\
\text { Nicobar } \\
\text { Islands }\end{array}$ \\
\hline
\end{tabular}

Table 1: Earthquake epicentres and magnitudes of the cases analyzed with pattern matching and image processing technique

For image processing technique for earthquake epicenter detection the Ionosphere Research Laboratory (IONOLAB) global TEC map data has been utilized. The TEC estimation method of IONOLAB group is the one of the most important contributions for ionospheric mapping and electron density reconstruction $(\mathrm{H}$. Tuna et al, 2014) regional model-based computerized ionospheric tomography using GPS measurements.

It is well known that ionospheric characteristics depends on different seasonal and variations of geomagnetic conditions. To study the seasonal variations of TEC, the seasonal median for different seasons are considered. From the experiment it is observed that due to the meridional wind flow during daytime from pole to the equator decrease the natural composition and $\mathrm{O} / \mathrm{N}_{2}$ ratio at the low latitude and results higher during equinox followed by the winter and lowest TEC in the summer. In the next step, for filtering unwanted geomagnetic influence on TEC variations of geomagnetic parameter $\mathrm{Kp}$ is considered for analysis for both high and low solar activity period. Based on Kp index typical quiet day and disturb day TEC data filtered out for both solar activity period. From the experiment it is also observed that during high solar activity period changes in the profile shape are clearly manually detectable but such a modification partially not visible during low solar activity period prior to an impending earthquake.

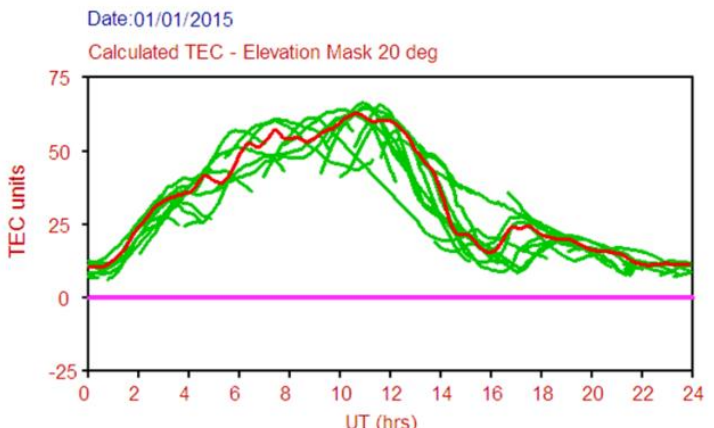

Figure 1: A typical TEC profile from IISC Bangalore station

It is noted that pre earthquake changes in TEC value at low latitude station occurs not only during the noon 
periods but also at post noon hours. Therefore it is necessary to analyze the seismic features of TEC for the entire day. To check the pattern of TEC profile pattern matching technique based on PIP is considered for earthquake time deviation in the entire TEC data for a day relation to quiet day. For this a template is formed for by selecting TEC profiles of quiet days for each month to filter out the geomagnetically disturbed factors. Earlier research reports that the anomaly enhancement of TEC peak occurs in not only during noon periods but also at post noon and after sunset hour prior to an impending earthquake (M Devi et al, 2012), which is an important mark along with the shape of profile in the new proposed method. The proposed pattern matching method for earthquake prediction is based on perceptually important point (PIP) identification. The whole method can be divided into two phrases, i.e. PIP identification and similarity measure. For the experiment, first compute the vertical total electron content $\triangle \mathrm{VTEC}$ for each day following formula:

$$
\Delta \text { VTEC }=\left(\frac{\Delta \rho}{40.3}\right)\left(\frac{f_{1}{ }^{2} \mathrm{xf}_{2}{ }^{2}}{{f_{1}}{ }^{2}-{f_{2}}^{2}}\right)
$$

where $\boldsymbol{\Delta} \boldsymbol{\rho}$ is the difference between time delays measured by the L1 and L2, $f_{1}$ is the frequency of $\mathrm{L} 1$ wave and $\mathrm{f}_{2}$ is the frequency of L2 wave.

Now for each month construct a template by taking moving average of 60 points. Now, compare the daily TEC data with the template for identification of earthquake precursor as follows:

At the first step compute Perceptually Important Points (PIP) for both the profiles. The first two PIPs will be the first and last points of the series say $\mathrm{p} 1=(\mathrm{x} 1, \mathrm{y} 1)$ and $\mathrm{p} 2$ $=(x 2, y 2)$ respectively. Measure the sum of the Euclidian distances (ED) of the test point say $\mathrm{p} 3=(\mathrm{x} 3$, $\mathrm{y} 3)$ to its adjacent PIPs $\mathrm{p} 1=(\mathrm{x} 1, \mathrm{y} 1)$ and $\mathrm{p} 2=(\mathrm{x} 2, \mathrm{y} 2)$, i.e. $\quad$ ED $=\sqrt{\left(\mathbf{x}_{2}-\mathbf{x}_{3}\right)^{2}+\left(\mathbf{y}_{2}-\mathbf{y}_{3}\right)^{2}}+$ $\sqrt{\left(x_{1}-x_{3}\right)^{2}+\left(y_{1}-y_{3}\right)^{2}}$

The second measure is the perpendicular distance (PD) between the test point $\mathrm{p} 3$ and the line connecting the two adjacent PIPs as shown in

$$
\begin{aligned}
& \operatorname{Slope}\left(p_{1}, p_{2}\right)=s=\frac{y_{2}-y_{1}}{x_{2}-y_{1}} \\
& \mathbf{x}_{\mathbf{c}}=\frac{\mathbf{x}_{3}+\left(\mathbf{s y}_{3}\right)+\left(\mathbf{s}^{2} \mathbf{x}_{2}\right)-\left(\mathbf{s y}_{2}\right)}{\mathbf{1}+\mathbf{s}^{2}}-\left(\mathbf{x}_{3}\right)^{2}
\end{aligned}
$$

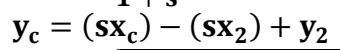

$$
\begin{aligned}
& P D\left(\mathbf{p}_{3}, \mathbf{p}_{\mathrm{c}}\right)=\sqrt{\left(\mathbf{x}_{\mathrm{c}}-\mathbf{x}_{3}\right)^{2}+\left(\mathbf{y}_{\mathrm{c}}-\mathbf{y}_{3}\right)^{2}}
\end{aligned}
$$

The final measure, is the vertical distance (VD) between the test point $\mathrm{p} 3$ and the line connecting the two adjacent PIPs, i.e $\boldsymbol{V D}\left(p_{3}, p_{c}\right)=\left|y_{c}-y_{3}\right|=\left|\left(y_{1}+\left(y_{2}-y_{1}\right) \frac{x_{c}-x_{1}}{x_{2}-x_{1}}\right)-y_{3}\right|$
where $\mathrm{x}_{\mathrm{c}}=\mathrm{x}_{3}$. After identifying the PIPs of the subsequence, a similarity measuring mechanism is essential for pattern matching. As different sequences may have different "amplitudes", after identifying the PIPs in the data sequence, it is necessary to re-scale the points so that the comparison between sequences in different "amplitudes" range (e.g. 0-1) can be facilitated. This is typically addressed as normalizing all the sequence values to a given range. Then, the amplitude distance $(\mathrm{AD})$ between $\mathrm{P}$ and $\mathrm{Q}$ can be computed by using point-to-point direct comparison, i.e.,

$$
A D(S P, Q)=\sqrt{\frac{1}{n} \sum_{k=1}^{n}\left(s p_{k}-q_{k}\right)^{2}}
$$

Here, SP and $\mathrm{sp}_{\mathrm{k}}$ denote the PIPs found in P. Now, consider the horizontal distortion of the pattern against the pattern templates. The temporal distance (TD) between $\mathrm{P}$ and $\mathrm{Q}$ is defined as

$$
\mathbf{T D}(\mathbf{S P}, \mathbf{Q})=\sqrt{\frac{1}{n-1} \sum_{k=2}^{n}\left(\mathbf{s p}_{k}^{\mathrm{t}}-\mathbf{q}_{\mathrm{k}}^{\mathrm{t}}\right)}
$$

where $\mathrm{sp}_{\mathrm{k}}^{\mathrm{t}}$ and $\mathrm{q}_{\mathrm{k}}^{\mathrm{t}}$ denote the time coordinate of the sequence points $\mathrm{sp}_{\mathrm{k}}$ and $\mathrm{q}_{\mathrm{k}}$, respectively. To take both horizontal and vertical distortion into consideration in our similarity measure, the distance (or similarity) measure could be modified as

$\mathbf{D}(\mathbf{S P}, \mathbf{Q})=\mathbf{w}_{\mathbf{1}} \cdot \mathbf{A D}(\mathbf{S P}, \mathbf{Q})+\left(\mathbf{1}-\mathbf{w}_{\mathbf{1}}\right) \cdot \mathbf{T D}(\mathbf{S P}, \mathbf{Q})$ In our next method we shall utilize an image segmentation technique for epicenter detection. Before the formal processing of the image, we perform some necessary preprocessing on the image to meet the requirements of the subsequent steps and achieve faster and better segmentation accordingly. The basic k-mean algorithm for image segmentation is discussed below:

Let us consider an image with resolution of $x \times y$ and the image has to be cluster into $k$ number of cluster. Let $\mathrm{p}(\mathrm{x}$, y)be an input pixels to be cluster and $c_{k}$ be the cluster centers. The algorithm for $\mathrm{k}$-means clustering is following as:

1. Initialize number of cluster $\mathrm{k}$ and centre.

2. For each pixel of an image, calculate the Euclidean distanced, between the center and each pixel of an image using the relation given below.

$$
\mathbf{d}=\left\|\mathbf{p}(\mathbf{x}, \mathbf{y})-\mathbf{c}_{\mathbf{k}}\right\|
$$

3. Assign all the pixels to the nearest centre based on distanced.

4. After all pixels have been assigned, recalculate new position of the centre using the relation given below

$$
\mathbf{c}_{\mathbf{k}}=\frac{1}{\mathbf{k}} \sum_{\mathbf{y} \in \mathbf{c}_{\mathrm{k}}} \sum_{\mathbf{x} \in \mathbf{c}_{\mathbf{k}}} \mathbf{p}(\mathbf{x}, \mathbf{y})
$$

5. Repeat the process until it satisfies the tolerance or error value.

6. Reshape the cluster pixels into image

\section{RESULTS AND DISCUSSIONS}

With the help of the above algorithms, now we shall proceed towards testing its application as a precursor and epicenter detection in few of earthquake cases. The earthquake events are considered so that the observing stations lies within the preparatory zone. In the first case, let us consider the earthquake event occurred in Bhutan (epicenter position: 27.320 N, 91.420 E) held on 21 September 2009 of magnitude $M=6.1$ occurred at 8.53UT. For this purpose, the nearest IGS station to the epicenter Lasha, Chaina $\left(29.6548^{\circ} \mathrm{N}, 91.1406^{\circ} \mathrm{E}\right)$ is considered for TEC data analysis. Figure 2 represents the TEC profile from 17 September to 21 September 2009 , i.e. prior to and during earthquake. From the profile, it can be clearly observed that the TEC profile shape pattern is fully different in 18 September i.e. three days before the earthquake event. 

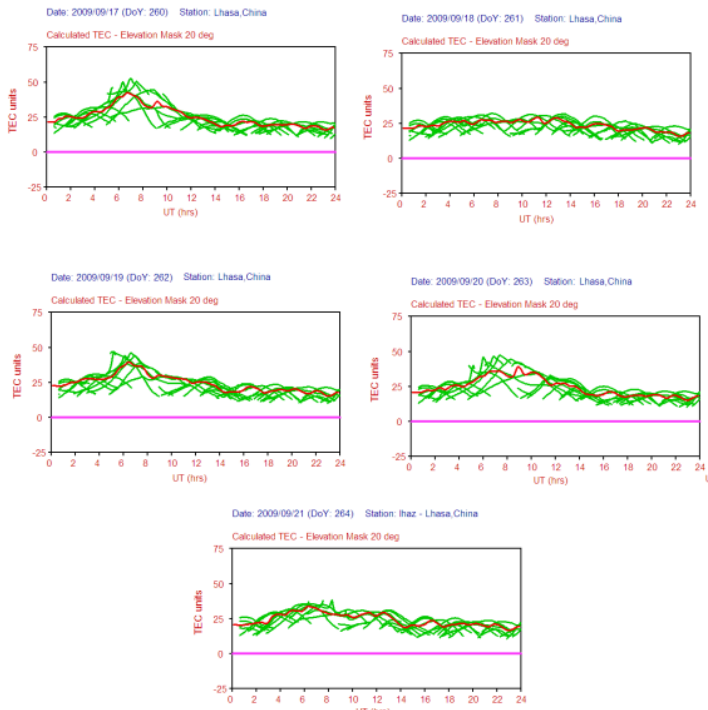

Figure 2: TEC profile shape from 17-21 September 2009 prior to and during Bhutan earthquake Station Lasha, Chaina

Now, for analyzing the event using the proposed method for similarity measure, one template is framed by using at least five quietest days of that month. The test is performed with a calculation of 'similarity percentage' for percentage matching of two time series and it is expected that the factor should be low before the earthquake event. The result is presented in figure 3 . The standard deviation of the 'similarity percentage' is also calculated for obtaining its maximum possible fluctuations for this month.

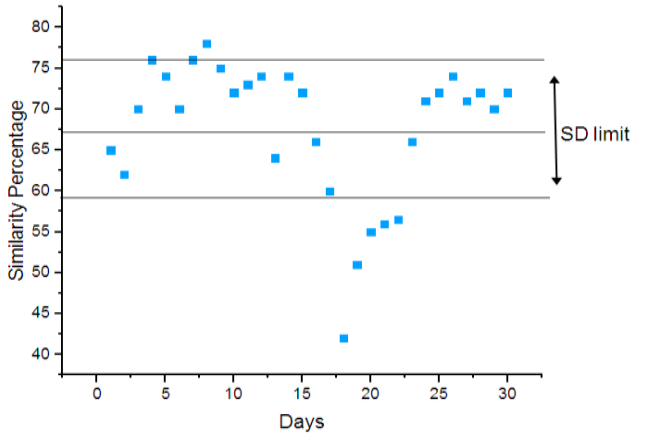

(a)

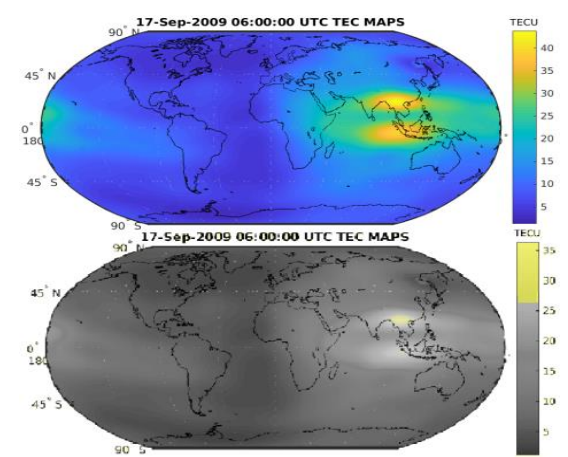

(b)

Figure 3: (a) 'Similarity percentage' for the month of September 2009, (b) Clustering result for 17 September 2009
From the above result (Figure 3a) one can clearly observe a clear drop of this factor prior to the earthquake. The second method using k-mean clustering results (Figure $3 b$ ) for epicenter detection produces a new cluster covering Lat $20-30^{\circ}$ Lon $88-120^{\circ}$. The cluster analysis is performed for each day prior to the earthquake and a better result is produced on September 17, 2009 five days prior to the event. The earthquake epicenter position $27.32^{\circ} \mathrm{N}, 91.42^{\circ} \mathrm{E}$ is fall inside the above grid.

To test the reliability of the above algorithms, the very strong earthquake of Yushu, China (epicentre at $33.165^{\circ} \mathrm{N} 96.629^{\circ} \mathrm{E}$ ) occurred on 13 April 2010 of magnitude $\mathrm{M}=7.1$ is considered for analysis, Lasha, Chaina lies well within the earthquake preparatory zone and is TEC data from this station considered for analysis. The Q-day template has been made for the month again and the 'Similarity percentage' is calculated and plotted in figure 4(a). Here too, one can easily observes a clear drop of similarity factor prior to the earthquake. The low values after the certainty factor after the earthquake event are interesting and may be associated with aftershocks. The clustering results (Figure $4 \mathrm{~b}$ ) also focus that there may be an earthquake event between Lat $20-36^{\circ}$ Lon $86-100^{\circ}$. Thus, both the two results of utilizing the algorithms for earthquake precursor and epicenter identification in TEC data are encouraging.

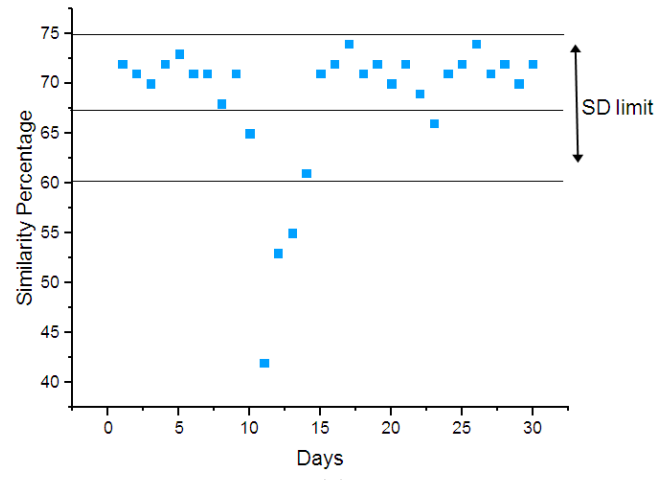

(a)

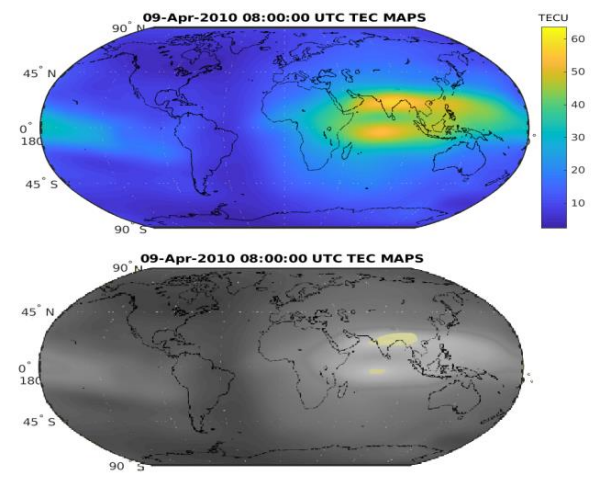

(b)

Figure 4: (a) 'Similarity percentage' for the month of April 2010, (b) Clustering result for 09 April 2010

The above technique is now applied for identifying the earthquakes of strong earthquake of 10 August, 2009 of Andaman Islands. The magnitude of the earthquake was $\mathrm{M}=7.5$ and was one of the strongest earthquake of Indian Ocean. For the analysis the data is collected from 
IGS Andaman and Nicobar Islands GPS station is considered and Q-day template has been made for the month accordingly. Here too, one can easily see a clear drop of similarity factor prior to the earthquake (Figure 5a). In this case, the clustering results produce two clusters and one is associated with 10 August, 2009 earthquake event and later one may be due to some other factor related to some geomagnetic events (Figure 5b). It is important to note that in all cases the profile shape is not influenced by increased electron density.

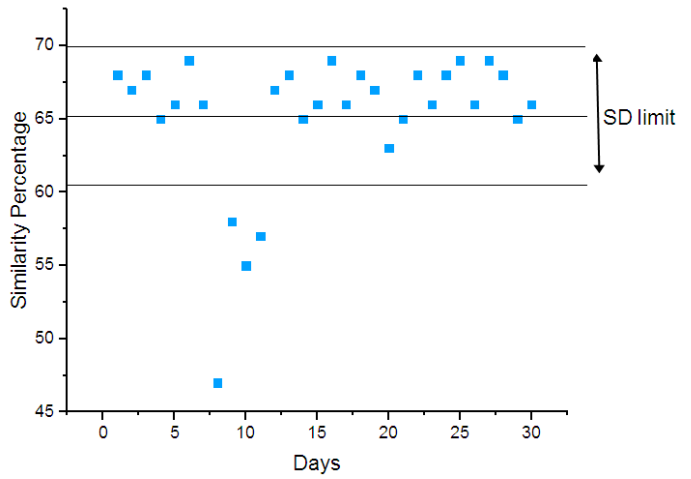

(a)

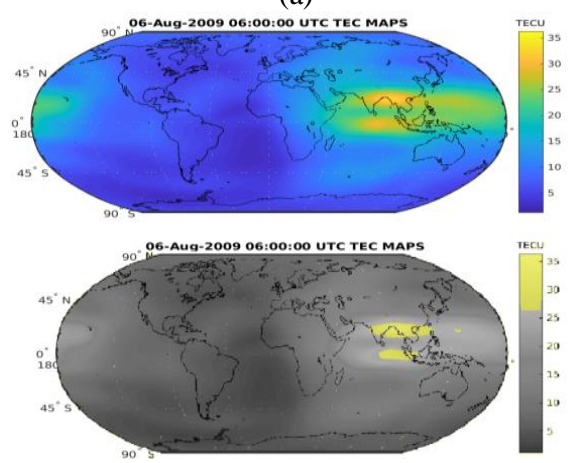

(b)

Figure 5: (a) 'Similarity percentage' for the month of August 2009, (b) Clustering result for 10 August 2009

Depueva reports that the analysis of TEC variation before an impending earthquake have shown that precursors at low-latitude stations are fully detectable as a kind of Appleton type EXB charge movement when the earthquake epicenter lies near to the equator (Depueva et.al., 1995). Again, the profile behavior of electron content as precursor imposed by an equatorial earthquake and low latitude earthquake may not be similar, since anomaly crest shift may lead to both increase and decrease of TEC, which depends on magnitude, closeness of the epicenter to the observing station. Past studies suggests that the TEC peak value analysis for prediction of an impending earthquake which is not reliable most of the time and produces false prediction results since the peak value is also associated with other factors (Devi et al, 2012). The Dynamic time warping method has also been applied to identify TEC anomalies related to earthquakes with low latitude TEC data (Devi et al., 2012), but this method suffers from the limitation in that it cannot resolve fine structure. On this background, an alternative method i.e pattern matching technique based on PIP for analysis of TEC data and an image processing technique for earthquake detection is applied successfully and earthquake precursor identification and detection of epicenter position in TEC using these methods are encouraging, though there are scopes for improvement (like without taking the moving average of the data), which will be included in our future studies.

\section{CONCLUSION}

In this paper an attempt is made for detecting earthquake cursor using TEC data using a pattern recognition algorithm, where variations in the entire 24hour profile of TEC are taken and an image processing method for epicenter detection. It is seen that the 'similarity factor' in the a pattern recognition technique has provided a tool for marking a cursor of moderate to strong earthquakes, when the observing station lies around the earthquake preparatory zone. The results are an improvement on prediction capability, compared to earlier Dynamic Time Series algorithm, since the earlier method has some limitations that it cannot resolve finer temporal and spatial information because of the enormous increase in size of the necessary matrix. The image processing technique based on $\mathrm{k}$ means constructs a cluster near to the epicenter. Our next attempt will be to make the technique for epicenter detection more efficient through use of multiple features of TEC such as azimuth and elevation angle position of the satellite and using other ionospheric parameter.

\section{REFERENCES}

Chen, M.Q. (2011) Observations and simulations of seismoionospheric GPS total electron content anomalies before the 12 January 2010 M7 Haiti earthquake. J. Geophys. Res. 116 (A04302). 1e9.

ChuoY.J.Y, .I.Chen, J.Y.Liu, S.A. Pulinets (2001) Ionospheric foF2 variations prior to strong earthquakes in Taiwan. Advances in Space Research. https://doi.org/10.1016/S0273-1177(01)00209-5.

Volume 27 Issues 6-7 Pages 1305-1310

C. Noll, The Crustal Dynamics Data Information System (2010) A resource to support scientific analysis using space geodesy, Advances in Space Research, Volume 45, Issue 12, Pages 1421-1440, ISSN 0273-1177, DOI: 10.1016/j.asr.2010.01.018.

Depueva, A. H. And Ruzhin, Yu. Ya (1995) Seismoionospheric fountain effect as analogue of active space experiment. Advances in Space Research. 15. pp. 151-154.

Dimitar, O., Pullinets, S., Alexey, R.A., Konstantin, T., Dimitri, D., Menas, K., Patrick, T. (2011) Atmosphereionosphere response to the M9 Tohoku earthquake revealed by multi instrument space-borne and ground observations: preliminary results. Earthq. Sci. 24. 1-7.

Dogan, U., Ergintav, S., Skone, S., Arslan, N., Oz, D. (2011) Monitoring of the ionosphere TEC variations during the 17th August 1999 Izmit earthquake using GPS data. Earth Planets Space. 63. 1183-1192.

Dutta, H.N., Dabas, R.S., Das, M.R., Sharma, K., Singh, B., (2007) Ionospheric perturbations over Delhi caused 
by the 26 December 2004 Sumatra earthquake. Int. J. Remote Sens. 28 (13-14). 3141-3151

E. Calais and J. B. Minster (1995) GPS Detection of Iono- spheric Perturbations Following the January 17, 1994, Northridge Earthquake. Geophysical Research Letters. Vol. 22. No. 9, pp. 1045-1048. doi:10.1029/95GL00168

G K. Davies and D. M. Baker (1965) Ionospheric Effects Ob- served Round the Time of Alaska Earthquake of March 28, 1964. Journal of Geophysical Research. Vol. 70. No. 9. pp. 2251-2263. doi:10.1029/JZ070i009p02251

J. Y. Liu, Y. I. Chen, S. A. Pulinets, Y. B. Tsai, Y. J. Chuo (2000) Seismo-ionospheric signatures prior to $\mathrm{M}>=6.0$ Taiwan earthquakes. Geophysical Research Letters. Vol. 27. No. 19. October 1. Pages 3113-3116 M Devi, AJD Sarma, S Kalita, AK Barbara, A Depueva, (2012) Adaptive techniques for extraction of pre-seismic parameters of Total Electron Content (TEC) at anomaly crest station. Geomatics, Natural Hazards and Risk. 3 (3). 193-206

M. Hayakawa (1999) Atmospheric and Ionospheric Electro- magnetic Phenomena Associated with Earthquakes. Terra Scientific Publishing Co, Tokyo

M. Hayakawa, O. A. Molchanov, T. Ondoh and E. Kawai (1996) The Precursory Signature Effect of the Kobe Earthquake on VLF Sub Ionospheric Signals. Journal of Communications Research Laboratory Tokyo. Vol. 43. 1996 pp. 169-180.

Priyadarshi, S., Kumar, S., Singh, A.K. (2011) Changes in total electron content associated with earthquakes
$(\mathrm{M}>5)$ observed from GPS station Varanasi, India. Geomatics, Nat. Hazard Risk. 2 (2). 123e139.

S. Kalita (2015) Monitoring the TEC variation using pattern matching method during earthquakes as determined from ground based TEC measurement and satellite data. Int. J. Sci. Res. Publications, vol. 5. no. 6. pp. 4.

Tuna H., O. Arikan, F. Arikan, T.L. Gulyaeva, and U. Sezen (2014) Online User-Friendly Slant Total Electron Content Computation from IRI-Plas: IRI-Plas-STEC. Space Weather. 12(1). 64-75. doi:10.1002/2013SW000998.

V. N. Oraevsky, Y. Y. Ruzhin and I. I. Shagimuratove (2000) Anomalies of Ionospheric TEC above Turkey before Two Strong Earthquakes. Proceedings of 15th Wroclaw EMC Symposium. Brugge. pp. 508-512.

Yuri Ruzhin, Costas Nomicos (2007) Radio VHF precursors of earthquakes. Nat Hazards. 006-9021-1. 40:573-583

DOI $10.1007 / \mathrm{s} 11069$

Zhang, Zhengh \& Liu, J \& Sun, J \& Wen, L \& Tapponnier, P \& Xing, X \& Xu, Qun \& Hu, Guyue \& Zeng, Lingsen \& Ding, Lin \& Ji, Chen \& Hudnut, Kenneth (2008) Co-seismic ruptures of the 12 May, 2008, Mw 8.0 Wenchuan earthquake, Sichuan: EW crustal shortening on oblique, parallel thrusts along the eastern edge of Tibet. AGU Fall Meeting Abstracts. 1. 0054 